\title{
O DESLOCAMENTO DA PEDAGOGIA DA QUALIFICAÇÃO PROFISSIONAL PARA A PEDAGOGIA DAS COMPETÊNCIAS NO MUNDO DO TRABALHO
}

\author{
THE DISPLACEMENT OF PROFESSIONAL QUALIFICATION PEDAGOGY TO \\ THE COMPETENCE PEDAGOGY IN THE WORK WORLD
}

Thaís Cristina Figueiredo Rego*

\section{RESUMO}

Este artigo tem como objetivo analisar questões relativas ao deslocamento da pedagogia da qualificação profissional para a pedagogia das competências no mundo do trabalho, a partir da reestruturação produtiva acelerada na década de 90 do século $\mathrm{XX}$. Além disso, pretende-se apontar os requisitos profissionais que passam a ser exigidos do trabalhador e que resultam na exigência de um novo perfil desse profissional. O referencial teórico proposto busca refletir como a formação profissional adapta-se às necessidades postas pela flexibilização do trabalho, articulando teoria e prática na formação do trabalhador para que este se torne polivalente, dominando um conjunto de conhecimentos e competências adaptandose à flexibilidade desejada pelo mercado de trabalho. Parte-se da premissa que as novas tecnologias organizacionais, baseadas nos critérios de flexibilidade e integração da produção, precisam de trabalhadores multifuncionais, capazes de manter altos níveis de produtividade, principalmente diante de situações que se modificam rapidamente. Enquanto o modelo de educação profissional baseado na qualificação forma para o desenvolvimento de um trabalho parcelado, com tarefas pré-determinadas o modelo baseado em competências propõe tornar as relações de trabalho, mas flexíveis e autônomas, devendo o trabalhador dominar o conhecimento de todo o processo de produção e não apenas das partes.

PALAVRAS-CHAVE: Reestruturação produtiva - Modelo de qualificação profissional - Modelo de competências - Formação profissional.

\section{ABSTRACT}

This article has the objective of analyze points related to displacement of professional qualification pedagogy to the competence pedagogy in the work world, as from the productive restructuration speeded up in the 90"s of the 20th century. Besides it, the intention is to indicate the professional requisites that shall become required from the worker and result in the requirement of a new profile of this professional. The theoretical referential proposed seeks to reflect how the professional formation suits to the necessities brought by the flexibility when it comes to work, articulating theory and practice in the worker formation so it becomes multifunctional, overpowering a group of knowledge and competences and adapting to the flexibility required by the work market. It"s believed that the organizational technologies, based on flexibility criteria and production integration, need multifunctional workers, capable to keep high 
productivity levels, mainly in situations that can change very fast. While the professional education model based on qualification leads to a fragmented work evolution, with predetermined tasks the model based on competences proposes the work relationships to become more flexible and independent, this way the worker can overpower the knowledge of the whole production process and not only parts.

KEYWORDS: Productive Restructuration - Professional qualification model Competences model - Professional formation

\section{INTRODUÇÃO}

Este artigo propõe analisar questões relativas ao deslocamento da pedagogia da qualificação profissional para a pedagogia das competências no mundo do trabalho, a partir da reestruturação produtiva acelerada na década de 90 do século $X X$.

O aumento do contingente profissional nas mais diversas áreas da indústria, do comércio e dos serviços a partir da década de 1930, obrigou o Estado a oferecer à população cursos capazes de capacitar os cidadãos e, assim oferecer oportunidades de inserção no mercado de trabalho.

Durante muito tempo toda essa formação se deu com foco na qualificação da força de trabalho. Ou seja, até o final da década de 1980 os trabalhadores formados pelas diversas instituições eram capacitados pelo chamado modelo de qualificação com características do modelo taylorista/fordista de organização e gestão do trabalho.

Para a realização de tais atividades eram exigidos do trabalhador conhecimentos mínimos relativos às operações matemáticas básicas, a leitura e escrita. Com poucos anos de escolaridade ele já se encontrava apto para o mercado de trabalho.

A revolução nas dimensões técnica e administrativa da organização do trabalho que chegou ao Brasil por volta de 1980 produziu grandes modificações em todos os aspectos da sociedade, particularmente no mundo do trabalho. Em resposta à essa crise, foi implantado nas indústrias um modelo japonês de produção voltado para a demanda do mercado, o toyotismo.

O trabalhador da indústria foi solicitado a deixar de ser um mero executor de tarefas parcializadas e a participar mais ativamente do conjunto da produção.

As novas tecnologias organizacionais, baseadas nos critérios de 
flexibilidade e integração da produção, precisavam de trabalhadores multifuncionais, criativos, com capacidade de comunicação e capazes de manter altos níveis de produtividade, principalmente diante de situações que se modificam rapidamente.

A discussão que se segue propõe apresentar as mudanças ocorridas no mundo do trabalho a partir da reestruturação produtiva, levando em consideração a formação do trabalhador no modelo fordista e no atual modelo das competências.

\section{O MODELO TAYLORISTA/FORDISTA DE ORGANIZAÇÃO E GESTÃO DO TRABALHO}

O taylorismo foi um modelo de gestão administrativa criado pelo engenheiro americano Frederick Winslow Taylor $(1856$ - 1915). Por meio de seus estudos constatou que os trabalhadores deveriam ser organizados de forma hierarquizada e sistematizada; que o trabalhador seria avaliado de acordo com sua produção e tempo e que, cada um deveria finalizar sua tarefa no menor tempo possível. Seus estudos ficaram conhecidos como a Teoria da Administração

Científica.

Taylor define em quatro os princípios fundamentais de sua teoria:

$1^{\circ}$ substituição do critério individual do operário por uma ciência;

2o seleção e aperfeiçoamento científico do trabalhador, que é estudado, instruído, treinado e, pode-se dizer, experimentado, em vez de escolher eles os processos e aperfeiçoar-se por acaso;

$3^{\circ}$ cooperação íntima da administração com os trabalhadores, de modo que façam juntos o trabalho, de acordo com leis científicas desenvolvidas, em lugar de deixar a solução de cada problema, individualmente, a critério do operário;

4ํe em lugar do antigo esforço individual, e com a divisão equânime, entre a direção e os trabalhadores, das partes de cada tarefa diária, a administração encarrega-se das atribuições para as quais está mais bem aparelhada e os operários das restantes. (TAYLOR, 1990, p. 84)

O empresário do ramo automobilístico, Henry Ford (1863-1947), seguindo a teoria de Taylor, aprimorou seu procedimento industrial na linha de montagem, gerando uma grande produção e consumo em massas; o chamado fordismo. Chiaventato (2003) coloca que, na produção em massa ou em série, o produto, o maquinário, o material e também a mão de obra devem ser padronizados o que proporciona um custo mínimo. O próprio Ford (s/d) define como o primeiro passo para o aperfeiçoamento da montagem trazer o trabalho ao operário ao invés de levar o 
operário ao trabalho (nada deve ser carregado mas tudo vir por si). Segundo ele são três os princípios de montagem.

1\%. Trabalhadores e ferramentas devem ser dispostos na ordem natural da
operação de modo que cada componente tenha a menor distância possível
a percorrer da primeira à última fase.
$2^{\circ}$. Empregar planos inclinados ou aparelhos recebidos de modo que o
operário sempre ponha no mesmo lugar a peça que terminou de trabalhar,
indo ela ter à mão do operário imediato por fôrça do seu próprio pêso sempre
que isso fôr possível.
$3^{\circ}$. Usar uma rede de deslisadeiras por meio das quais as peças a montar se
distribuam a distâncias convenientes. (FORD, s/d, p.70)

Ford acreditava que obteria com essas normas a economia de pensamento e a redução ao mínimo dos movimentos do operário (estes devem fazer sempre uma coisa de cada vez e com um só movimento).

A união desses dois modelos ficou conhecida como modelo taylorista/fordista de organização e gestão do trabalho e tinha como características a produção em massa, através da linha de montagem e de produtos mais homogêneos, controle dos tempos e movimentos pelo cronômetro taylorista e produção em série fordista, trabalho parcelar e, principalmente a fragmentação das funções: separação entre elaboração e execução no processo de trabalho (heterogestão).

De acordo com Bihr (2010, p. 40),

no taylorismo e no fordismo, o saber e a habilidade operários tendem a ser monopolizados pelo staff administrativo ou até mesmo a ser diretamente incorporados ao sistema de máquinas, provocando a expropriação dos operários em relação ao domínio do processo de trabalho e uma maior dependência em relação à organização capitalista do trabalho.

Bihr coloca ainda que essa consolidação da dominação do capital sobre o processo de trabalho vai permitir a intensificação da exploração da força de trabalho operária. A parcelização do trabalho operário permite aumentar a destreza de cada operário, sua habilidade na execução de alguns gestos elementares, mas também reduz o "tempo morto"; o que causa o aumento da intensidade do trabalho. Se antes, a produção era de característica extensiva, ou seja, baseado na formação da maisvalia absoluta (extração do trabalho excedente através do aumento de sua intensidade e duração), a partir dessa união tem-se um regime com característica intensiva, orientado para a formação da mais-valia relativa (aumento do trabalho excedente pela diminuição do tempo de trabalho necessário à reprodução da força de 
trabalho do proletariado, graças ao aumento contínuo da produtividade média do trabalho social).

Esse modelo perdurou até o final da década de 1960 e início dos anos de $1970^{1}$, nesse período os trabalhadores eram formados em instituições que baseavam seu ensino na capacitação da força de trabalho de acordo com o chamado modelo de qualificação, que possuía características do regime taylorista/fordista de organização e gestão do trabalho.

No Brasil, contextualizamos a formação da força de trabalho dentro desse modelo durante a chamada "Era Vargas", ou Estado Novo, que começa com a Revolução de 1930 e termina com a deposição de Getúlio Vargas em 1945. Esse período foi marcado pelo aumento gradual da intervenção do Estado na economia e na organização da sociedade e também pelo crescente autoritarismo e centralização do poder.

Durante o Estado Novo ocorreram mudanças no Brasil e no mundo, que influenciaram a industrialização nacional. Os problemas decorrentes da queda da bolsa de Nova lorque, 1929 e a crise cafeeira que se sucedeu no Brasil naqueles anos, desencadearam na década de 1930 um maior contingente de profissionais nas mais diversas áreas da indústria, do comércio e dos serviços. Seria necessário criar soluções para aperfeiçoamento dessa força de trabalho, principalmente para suprir a demanda de trabalhadores qualificados para os setores industriais, comerciais e de serviços ${ }^{2}$.

O modelo taylorista/fordista possibilitou a acumulação capitalista e acelerou a história humana, principalmente no que tange ao desenvolvimento das ciências e das tecnologias.

Conforme, Marx e Engels no Manifesto Comunista de 1848:

[...] as velhas indústrias nacionais foram destruídas e continuam a sê-lo diariamente. São suplantadas por novas indústrias, cuja introdução se torna uma questão vital para todas as nações civilizadas, indústrias que não empregam mais matérias-primas nacionais, mas sim matérias-primas vindas das regiões mais distantes, cujos produtos se consomem não somente no próprio país, mas em todas as partes do globo. Em lugar das antigas necessidades, satisfeitas pelos produtos nacionais, nascem novas necessidades que reclamam para sua satisfação os produtos das regiões mais longínquas e dos climas mais diversos. Em lugar do antigo isolamento das regiões e nações que se bastavam a si próprias, desenvolve-se um intercâmbio universal, uma universal interdependência das nações. $E$ isso se refere tanto à produção material como intelectual. [...] Devido ao rápido aperfeiçoamento dos instrumentos de produção e ao constante progresso 
dos meios de comunicação, a burguesia arrasta para a torrente da "civilização" mesmo as nações mais bárbaras. Os baixos preços de seus produtos são a artilharia pesada que destrói todas as muralhas da China e obriga a capitularem os bárbaros mais tenazmente hostis aos estrangeiros.

Sob pena de morte, ela obriga todas as nações a adotarem o modo burguês de produção, constrange-as a abraçar o que ela chama de civilização, isto é, a se tornarem burguesas. Em uma palavra, cria um novo mundo à sua imagem e semelhança (MARX \& ENGELS, 1980, p. $12-$ 13, grifos da autora).

A engenharia produtiva fordista baseia sua eficácia num tipo de organização nas indústrias em que os postos de trabalho são parcializados ${ }^{3}$ e encadeados, incorporando uma força de trabalho maciçamente formada por operadores semiqualificados, com ritmo intenso de trabalho, tarefas simples, rotineiras e previamente especializadas. Já que os trabalhadores, nessa organização, não têm autonomia e pouco intervém no processo produtivo, sua formação e treinamento requer pouco tempo e custo (CORIAT apud DELUIZ, 1995). Kuenzer (2002b) concorda com isso ao dizer que o trabalhador herda, por toda vida, uma única função dentro da empresa tendo suas tarefas adaptadas às suas habilidades naturais e adquiridas. Há o aparecimento de uma classe trabalhadora sem qualquer habilidade especial, para executar operações simples que qualquer um pode desempenhar; para estes não há custos de aprendizagem; para os que têm alguma qualificação o custo de formação parcializada é inferior ao necessário à formação completa, consequentemente há a queda do custo da força do trabalho.

No modelo taylorista/fordista, ou modelo de qualificações, as relações entre educação e trabalho são medidas por atividades operacionais. Segundo Kuenzer (1999b, p. 24)

\begin{abstract}
o trabalhador era considerado qualificado quando executava tarefas com habilidade, geralmente adquirida pela combinação entre treinamento e experiência, que se dava através da mediação das atividades laborais. Em decorrência da natureza dos processos técnicos, transparentes, rígidos e estáveis, bastavam habilidades psicofísicas, memorização e repetição de procedimentos para definir a capacidade para executar determinadas tarefas, cujas variações pouco significativas ao longo do tempo permitiam uma adaptação quase "natural" às mudanças.
\end{abstract}

Para a realização de tais atividades não eram requeridos do trabalhador 
conhecimentos maiores que os de calcular, ler e escrever, ou seja, com poucos anos de escolaridade ele já se encontrava apto para o mercado de trabalho. O conhecimento era tido como passível de ser explicitável ou conceitualizado. É o que Fidalgo e Fidalgo (2007, p.34) chamam de conhecimento explícito "composto por formalização mental e física, sendo possível identificar e externalizar o meio pelo qual (processo) se construiu determinado conhecimento".

No modelo de qualificação as instituições de ensino tinham como função especializar o trabalhador em uma determinada fase da produção, dentro de um ramo industrial também determinado. Isso quer dizer que, no modelo taylorista/fordista, temos a produção ligada aos postos de trabalho, com regras bastante objetivas no que diz respeito ao tipo de trabalhador esperado. $O$ trabalhador deveria demonstrar atributos próprios do setor produtivo em que fosse atuar. As escolas e cursos de formação profissional, de acordo com as qualificações exigidas pelo mercado, delineavam o perfil profissional.

Para melhor entendimento, torna-se importante a definição do termo qualificação tão presente nos modos de produção taylorista/fordista:

O uso mais corrente do termo qualificação se relacionou aos métodos de análise ocupacional, que visavam identificar as características do posto de trabalho e delas inferir o perfil ocupacional do trabalhador apto a ocupá-lo. [...] o termo qualificação esteve associado tanto ao processo quanto ao produto da formação profissional, quando visto pela ótica da preparação da força de trabalho. Nesse sentido, um trabalhador desqualificado poderia a vir a ser qualificado para desempenhar determinadas funções requeridas pelo posto de trabalho por meio de cursos de formação profissional. (RAMOS, 2006, p.34)

E, ainda:

A qualificação está apoiada sobre dois sistemas: a) as convenções coletivas, que classificam e hierarquizam os postos de trabalho; b) o ensino profissional, que classifica e organiza os saberes em torno dos diplomas. Nota-se, portanto, que o conceito de qualificação nasce de forma correlata e consolida-se com o modelo taylorista-fordista de produção, em torno do qual se inscrevem tanto os padrões de formação quanto os de emprego, carreira e remuneração. (RAMOS, 2006, p. 42)

Dessa maneira, o diploma proporcionava ao seu portador uma carreira linear e crescente. Para preencher as exigências dos postos de trabalho, bastava ao trabalhador demonstrar que suas qualidades encaixavam-se perfeitamente às 
necessidades da empresa. Sua formação garantia um conjunto de características objetivas das rotinas de trabalho, adquiridas com o tempo de aprendizagem ou do conhecimento das técnicas envolvidas em uma dada operação.

O trabalhador desejado à época do taylorismo era o "trabalhador boi", tal como foi definido por Taylor (TAYLOR, 1990), ou seja, um ser que não reflete sobre seu trabalho, que se submete passivamente às ordens da hierarquia superior e ao controle de seus tempos e movimentos na execução de seu trabalho; que respeita os rígidos códigos de disciplina das empresas e que realiza repetidamente o trabalho característico de seu posto sem se sublevar contra isso. Esse tipo de trabalhador tinha sua subjetividade negada, nem seu pensar ou sua intelectualidade eram considerados, ele era, simplesmente, uma extensão da máquina.

Segundo Ferreira (1997) o padrão de crescimento industrial fordista, que havia mantido sua eficácia desde o final da segunda grande guerra, começou a perder dinamismo no final da década de 1960. Os ritmos de crescimento da atividade econômica e da produtividade do trabalho diminuíram, as taxas de rentabilidade e os níveis de emprego caíram, observando-se aumentos dos níveis de capacidade ociosa da força de trabalho e emergiram pressões inflacionárias na maioria das economias capitalistas. Desse modo, como sistema de produção, o fordismo tornou-se improdutivo pela sua incapacidade de gerar ganhos de produtividade.

O esgotamento da estratégia de regulação social exercida pelo fordismo foi contemporâneo à crise do Estado de bem-estar social. Este esgotamento do modelo fordista, coordenado pelas políticas de Estado voltadas para o campo social (crise do fordismo, crise de estado de bem-estar social) deveu-se, principalmente, à secundarização do elo entre reprodução do capital e trabalho, até então sustentado pelos acordos de produtividade (FEHER apud DELUIZ, 1995). A partir de então, foram introduzidas algumas alterações econômicas, sociais e políticas na organização do trabalho e, com a chegada das novas tecnologias, na década de 1980, houve uma reversão enorme nesse quadro.

Essa crise, de acordo com Antunes (2008), afetou tanto a materialidade da classe trabalhadora, a sua forma de ser, quanto a sua subjetividade, o universo dos seus valores, do seu ideário, que pautam suas ações e práticas concretas. Ainda segundo esse autor, ela fez com que o capital implementasse um vastíssimo processo 
de reestruturação, com vistas à recuperação do seu ciclo de reprodução e que afetou fortemente o mundo do trabalho.

\section{A REESTRUTURAÇÃO PRODUTIVA E O MODELO DE COMPETÊNCIAS}

A revolução nas dimensões técnica e administrativa da organização do trabalho, que vem se operando em nível mundial desde os anos 1970, chegando ao Brasil por volta de 1980, produziu grandes modificações em todos os aspectos da sociedade, particularmente no mundo do trabalho.

Em resposta à essa crise, foi implantado nas indústrias um modelo japonês de produção voltado para a demanda do mercado, o toyotismo. Para Ohno 4

(1997, p. 23) "uma empresa não poderia ser lucrativa usando o sistema convencional de produção em massa americano que havia funcionado tão bem por tanto tempo". São considerados os pilares do Sistema Toyota de Produção:

$1^{\circ}$. "Just-in-time significa que, em um processo de fluxo, as partes corretas necessárias à montagem alcançam a linha de montagem no momento em que são necessários e somente na quantidade necessária." (p. 26)

$2^{\circ}$. Autonomomação: Dar à máquina inteligência humana. "A autonomação também muda o significado da gestão. Não será necessário um operador enquanto a máquina estiver funcionando normalmente. Apenas quando a máquina pára devido a uma situação anormal é que ela recebe atenção humana. Como resultado, um trabalhador pode atender diversas máquinas, tornando possível reduzir o número de operadores e aumentar a eficiência da produção." (OHNO, 1997)

No toyotismo (ANTUNES, 2008), a produção variada e diversificada existe para suprir o consumo. Esse modelo apresenta estoque mínimo da produção através da adoção do just in time ${ }^{5}$. Outras características do toyotismo são: aumento da quantidade de máquinas operadas por um único trabalhador, requerimento de uma força de trabalho multifuncional, execução do trabalho em equipe, reposição e atualização constante do maquinário para que novos produtos sejam produzidos.

Nas últimas décadas, particularmente a partir de 1980, o mundo do trabalho vivenciou uma situação fortemente crítica, intensificaramse as transformações no processo produtivo, o que afetou diretamente a esfera educacional; principalmente a direcionada à formação profissional. 
O termo qualificação adquire, hoje, uma nova configuração, uma vez que o mercado exige uma força de trabalho detentora de saberes mais holísticos. deslocamento do conceito de qualificação para competências seria possível uma vez que acontece uma nova configuração nas formas de trabalho, redução ou fechamento de postos de trabalho e valorização da subjetividade do trabalhador.

Ramos (2005) e Deluiz (1995) colocam que a competência não substitui o conceito de qualificação. Para elas, o que há é um deslocamento conceitual, pois a competência tanto reforça quanto nega as dimensões existentes no conceito de qualificação. "Não obstante, a noção de competência não substitui ou supera o conceito de qualificação. Antes, ela o nega e o afirma simultaneamente, por negar algumas de suas dimensões e afirmar outras." (RAMOS, 2005, p. 41)

Nesse paradigma o homem, enquanto trabalhador, é obrigado a aceitar o desemprego em massa e/ou estrutural, a falta de qualidade de vida e a contínua precarização do trabalho. O trabalho passa a ser algo abstrato para o homem, mesmo empregando sua força de trabalho na produção, o homem não percebe o que produziu, o trabalho assume o controle do homem. É o que Braverman expressa ao dizer que a massa humana está submetida ao processo de trabalho para os fins daqueles que a controlam mais que para qualquer fim geral de "humanidade" como tal. Ao adquirir assim forma concreta, o controle humano sobre o processo do trabalho converte-se no seu contrário, e vem a ser o controle do processo de trabalho. (BRAVERMAN, 1987, p. 167)

Dessa forma, presenciamos uma desumanizante alienação onde o trabalho ao mesmo que humaniza o homem, também o animaliza enquanto manifestação do trabalho alienado.

\footnotetext{
A alienação transforma a atividade espontânea no "trabalho forçado", uma atividade que é um simples meio de obter fins essencialmente animais (comer, beber, procriar), e com isso "o animal se torna humano, e o humano, animal. Para piorar as coisas, mesmo essa forma alienada de atividade - necessária que é à mera sobrevivência - é com freqüência negada ao trabalhador, porque "o trabalho mesmo se torna um objeto, do qual o trabalhador só pode se apossar com os maiores esforços e com as mais extraordinárias interrupções". (MÉSZÁROS, 2006, p. 146)
}

Sendo assim, o trabalho constitui duas faces de uma mesma moeda: de um lado pode ser caracterizado como uma atividade humana auto-realizadora e do outro aliena o homem através da exploração da sua força de trabalho diminuindo, assim, o 
valor humano. Para Mészáros (2006, p. 146), o trabalho, que deveria ser uma propriedade interna, ativa, do homem, se torna exterior ao trabalhador devido à alienação capitalista ("o trabalho é externo ao trabalhador, isto é, não pertence ao seu ser [...] O trabalhador só se sente, por conseguinte e em primeiro lugar, junto a si [quando] fora do trabalho e fora de si [quando] no trabalho")

O chamado "modelo de competência" aparece nas empresas para orientar a formação da força de trabalho de acordo com a organização do trabalho adotado pela organização. Esse conceito é contraposto ao de qualificação profissional, mas tem conotações diferentes, na medida em que enfatiza menos a posse dos saberes técnicos e mais a sua mobilização para a resolução de problemas e o enfrentamento de imprevistos na situação de trabalho, tendo em vista a maior produtividade com qualidade. (FERRETTI, 1997)

O modelo proposto pela qualificação propõe uma visão mais estática do mundo do trabalho, em que a trajetória profissional associa promoção ao aumento do conhecimento técnico e da responsabilidade com uma correspondente elevação da hierarquia salarial; o modelo de competência indica novos modos de produção, exige dinamicidade e, as formas de gestão do trabalho, fazem incidir sobre os próprios trabalhadores a responsabilidade por gerar condições de promoção.

Segundo Santos e Fidalgo (2007, p. 76)

até a década de 1980 foi possível a utilização de uma mão-de-obra com
baixo nível de qualificação, os novos tempos estariam indicando a
necessidade de uma forte elevação do nível de escolarização de modo a
permitir que os trabalhadores acompanhem os processos de trabalho em
contínua mutação.

Com as modificações advindas das transformações do sistema produtivo, a partir da década de 1980 (década caracterizada por um grande salto tecnológico), observa-se modificações no campo de formação e capacitação dos trabalhadores. A onda de inovações tecnológicas caracteriza o processo de reestruturação nas empresas brasileiras e no plano do trabalho, ocorre o deslocamento do conceito de qualificação em direção ao conceito de competência.

Mas, se por um lado a tecnologia aumenta a capacidade humana, por outro sacrifica indivíduos, criando bolsões de pobreza e colocando milhares à margem do processo produtivo. Marx coloca que ao mesmo tempo em que a tecnologia é uma 
vitória do homem sobre a natureza ela contribui para sua dominação, exploração e expropriação:

A maquinaria, como instrumental que é, encurta o tempo de trabalho; facilita
o trabalho; é uma vitória do homem sobre as forças naturais; aumenta a
riqueza dos que realmente produzem; mas, com sua aplicação capitalista,
gera resultados opostos: prolonga o tempo de trabalho, aumente sua
intensidade, escraviza o homem por meio das forças naturais, pauperiza os
verdadeiros produtores. (MARX, 2010, p. 503)

Mészáros argumenta que mais importante do que saber se a ciência e a tecnologia são utilizadas para resolução dos nossos problemas, mas se seremos capazes de direcioná-las para a não perpetuação do atual modelo capitalista:

Argumentar que "ciência e tecnologia podem solucionar todos os nossos problemas a longo prazo" é muito pior do que acreditar em bruxas, já que tendenciosamente omite-se o devastador enraizamento social da ciência e da tecnologia atuais. Também nesse sentido, a questão central não se restringe a saber se empregamos ou não a ciência e a tecnologia com a finalidade de resolver nossos problemas - posto que é óbvio que devemos fazê-lo -, mas se seremos capazes ou não de redirecioná-las radicalmente, uma vez que hoje ambas estão estreitamente determinadas e circunscritas pela necessidade da perpetuação do processo de maximização dos lucros. (MÉSZÁROS, 2009, p. 53)

O trabalhador da indústria foi solicitado a deixar de ser um mero executor de tarefas parcializadas e a participar mais ativamente do conjunto da produção. Assim, diante dessas mudanças, compreender o termo competência é tarefa importante para entender o novo paradigma que orienta a formação de trabalhadores nesta etapa do capitalismo.

Com a competência tomam lugar o saber-fazer proveniente da experiência, os registros provenientes da história individual ou coletiva dos trabalhadores, ao lado dos saberes mais teóricos tradicionalmente valorizados na lógica da qualificação. Enfim, fundamentada sobre a valorização da implicação subjetiva no conhecimento, ela desloca a atenção para a atitude, o comportamento e os sabres tácitos dos trabalhadores. (RAMOS, 2006, p. 66)

Gonzales (apud SOARES, 1997) aponta que a noção de competência, sendo mais abrangente do que a de qualificação, envolve tanto a experiência adquirida na vida e no trabalho quanto o conhecimento formal adquirido na escola. $E$, diferentemente da qualificação, a qual envolve um processo preciso e terminal, a aquisição de competências é complexa, longa e pressupõe uma ampla base de 
educação geral. A autora considera ainda que, atualmente, uma formação de qualidade para os trabalhadores não deve se restringir a atender somente às exigências do mercado, mas deve ser suficientemente inovadora para influenciá-lo.

Acontece uma valorização do conhecimento tácito, aquele relacionado com a intuição e que não pode ser explicado. Nesse tipo de conhecimento o importante é o saber-fazer (experiências) e o saber-ser. Seu foco está no comportamento, no que o trabalhador traz dentro de si e, que muitas vezes, não é capaz de externá-lo ou passá-lo adiante, consegue somente colocá-lo em prática na sua rotina de trabalho. O conhecimento tácito é de difícil explicação e formulação até para quem o possui. Hoje, tornou-se comum encontrarmos trabalhadores em postos de trabalho que nada tem a ver com sua formação técnica, mas que por apresentarem determinadas características subjetivas conseguem desempenhar com êxito sua função.

De acordo com Lucena (2010, p. 34) há que se ter cuidado com a utilização do conhecimento tácito, pois

\begin{abstract}
quando problematizamos a relevância do conhecimento tácito, verificamos suas preocupações girarem em tomo apenas da contínua produtividade, uma divisão social do trabalho que não rompe com a lógica alienante do trabalho e se apresenta dentro das fronteiras do positivismo durkheimiano. Isso se explica pela distinção entre a teoria e a prática, a ação e a execução, o saber e o fazer. Essa concepção aponta o conhecimento tácito nas fronteiras do "fazer despolitizado": uma valorização positivista da função social que tem suas bases em uma noção de "experiência profissional despolitizada".

[...]

É um lembrete do fazer ao saber, pois aponta a dependência e os limites do trabalho morto em relação ao trabalho vivo, afirmando, assim, que os homens são essenciais no trabalho. Ele existe independente da escola formal, pois se constrói de uma forma empírica, através de um processo histórico que se consolida a partir da relação entre o homem e a máquina. (LUCENA, 2010, p. 35 e 36).
\end{abstract}

O processo de produção orientado de acordo com a demanda, e não mais com a oferta de produtos e serviços, exigiu modificações rápidas na forma de organizar o trabalho de modo a obter respostas ágeis dos trabalhadores na lida com as novas condições de produção. As novas tecnologias físicas, de base microeletrônica, passaram a demandar, para sua potenciação, trabalhadores que pudessem explorar suas várias possibilidades. As novas tecnologias organizacionais, baseadas nos critérios de flexibilidade e integração da produção, precisavam de trabalhadores multifuncionais, criativos, com capacidade de comunicação e capazes 
de manter altos níveis de produtividade, principalmente diante de situações que se modificam rapidamente. As novas condições de realização do trabalho requeriam, portanto, um trabalhador que pudesse se manter produtivo, mesmo em condições de trabalho que se alteram com grande frequência.

Portanto, com a mudança do conceito de qualificação para competência, não se trata mais de uma qualificação formal/ qualificação para desenvolver tarefas relacionadas a um posto de trabalho, mas da qualificação real, ou seja, novas formas de organização do trabalho requerem dos trabalhadores procedimentos cada vez mais coletivos, além do domínio de conteúdos e de metodologias que possibilitem a resolução de problemas novos de modo original (KUENZER, 2000).

Esse novo modelo pautado nas competências, provoca reviravoltas nas agências de formação profissional, e segundo Ferreti (1997, p.234)

\begin{abstract}
as fortes demandas por qualificação atualizada e contínua, destinada a um contingente maior de trabalhadores e não apenas aos ocupantes de postoschave e, ao mesmo tempo, articulada com a introdução de inovações tecnológicas, têm conduzido as agências a promover uma alteração de porte na oferta de modalidades de capacitação, "mudando a ênfase da formação inicial [para] a formação complementar, a qual inclui cursos de especialização, atualização e complementação".
\end{abstract}

Ainda segundo esse autor, algumas das transformações

mais significativas dizem respeito à progressiva extinção da

modalidade de aprendizagem, à concentração de esforços na formação de técnicos, à instalação de cursos de curta duração e ao investimento em atividades de assessoria técnica a empresas.

É a posse das características inerentes ao modelo de competências que vai dizer que capacitação precisa o trabalhador para cada situação, quantidade e por quanto tempo, tendo como objetivos racionalizar, otimizar e adequar a força de trabalho às demandas do sistema produtivo.

Ferreti atribui ao capital o interesse em incutir nos sujeitos a valorização do mérito individual, a mudança, a flexibilidade, a insatisfação "saudável" com o nível de aperfeiçoamento conseguido e a competição.

Assim, aos ganhos para a empresa decorrentes da utilização de tais atributos na produção de bens ou serviços, soma-se a transferência para o trabalhador da responsabilidade por sua contínua formação, sem o que será 
visto como não identificado com os objetivos institucionais e, portanto, responsável pela sua própria demissão. (FERRETI, 2005, p. 112)

O trabalho passa a ser responsável não só pela sua demissão, mas também pela sua condição de manter-se empregado e útil ao mercado. Marx (2004, p.24) já observava esse tipo de precarização do trabalho.

Para Antunes (2008), a intensa precarização existente atualmente no mundo do trabalho demonstra um processo maior de hetorogeinização, fragmentação e complexificação da classe trabalhadora. Essa precarização inclui ainda: aumento significativo do trabalho assalariado, principalmente no setor de serviços; diminuição da classe operária industrial tradicional; aumento da força de trabalho feminino (heteregeinização do trabalho); grande expansão do trabalho parcial, temporário e subcontratado; aumento da terceirização dos serviços e ainda ampliação do desemprego estrutural ${ }^{6}$.

A educação tende a adaptar-se ao referencial da flexibilização e da globalização estando diretamente ligada às necessidades do setor produtivo, no que diz respeito à formação do trabalhador. Ela acaba por repetir as relações de dominação e submissão existentes no modo capitalista.

\begin{abstract}
Entende-se, pois, que a educação ainda se revela, no século XXI, restrita a um papel compensatório, mostrando-se - num momento marcado por incertezas, por diversas formas de precarização das condições de existência e por fortes processos de exclusão -, sob uma forma ideológica de "novo tipo", que constrói uma nova sociabilidade, moldada pela lógica mercantil e que coloca sobre os indivíduos a responsabilidade pelo alcance de melhor qualidade de vida. (FRANÇA, 2008, p. 172)
\end{abstract}

A busca desenfreada por cursos de capacitação, a necessidade constante de realização de novos cursos e o investimento frequente no aperfeiçoamento dos conhecimentos técnicos, demonstra que o trabalhador enxerga nos processos educativos uma forma de melhora da renda e equalização social. Para Schultz apud Frigotto (2001), "o componente da produção, decorrente da instrução, é um investimento em habilidades e conhecimentos que aumenta futuras rendas e, desse modo, assemelha-se a um investimento em (outros) bens de produção." 
As mudanças ocorridas no mundo do trabalho demonstram também como valores e concepções da classe dominante, são moldados e implantados com intensidade em milhões de consciências.

A seguir analisaremos como as mudanças no mundo do trabalho requerem novas demandas de educação, principalmente no que tange à formação profissional.

\section{CONSIDERAÇÕES FINAIS}

O mercado de trabalho conta hoje com uma classe trabalhadora bastante heterogênea, complexa e diversa. Não podemos nos esquecer que nossa força de trabalho encontra-se dividida em trabalhadores qualificados e desqualificados presentes no mercado formal e informal. São milhões de brasileiros divididos entre negros, brancos, jovens, velhos, homens e mulheres; todos em busca de oportunidades para demonstrarem seu valor perante a sociedade.

As mudanças ocorridas no mundo do trabalho demonstram também como valores e concepções da classe dominante, são moldados e implantados com intensidade em milhões de consciências.

Se por um lado a tecnologia aumenta a capacidade humana, por outro sacrifica indivíduos, criando bolsões de pobreza e colocando milhares à margem do processo produtivo.

É certo que as mudanças estão aí e o Brasil não pode ficar aquém dessas transformações. Faz-se necessário entender o processo de reestruturação produtiva e como o trabalhador se insere nesse contexto para compreender e definir como a educação profissional, poderá contribuir para a formação desse novo perfil de força de trabalho.

\section{REFERÊNCIAS BIBLIOGRÁFICAS}

ANTUNES, Ricardo. Adeus ao trabalho?: ensaio sobre as metamorfoses e a centralidade do mundo do trabalho. 13. ed. rev. ampl. São Paulo: Cortez, 2008. 
AZEREDO, Beatriz. Políticas Públicas de Emprego: a experiência brasileira. São Paulo: Associação Brasileira de Estudos do Trabalho - ABET, v. 1. 1998. (Coleção Teses \& Pesquisas)

BIHR, Alain. Da grande noite à alternativa. 2. ed. São Paulo: Boitempo, 2010. 284p.

CHIAVENATO, Idalberto. Introdução à teoria geral da administração. Rio de Janeiro: Elsevier, 2003.

DELUIZ, Neise. Formação do trabalhador: produtividade e cidadania. Rio de Janeiro: Shape, 1995.

FERREIRA, Cândido Guerra. O fordismo, sua crise e o caso brasileiro. In: Cadernos do CESIT/UNICAMP, Campinas, n. 13, 1997.

FERRETI, Celso João. Formação profissional e reforma do ensino técnico no Brasil: anos 90. In: Educação e Sociedade. Ano XVIII, n. 59, ago./ 1997.

FIDALGO, Fernando; OLIVEIRA, Maria Auxiliadora Monteiro; FIDALGO, Nara Luciene Rocha. Educação Profissional e a lógica das competências. Petrópolis, Rio de Janeiro: Vozes, 2007.

FORD, Henry. Minha vida e minha obra. Trad. Monteiro Lobato. Rio de Janeiro: Brand, s/d.

FRANÇA, Robson Luiz de. O trabalhão como princípio da dignidade da pessoa humana: Estado, educação e cidadania. In: LUCENA, Carlos (org). Capitalismo, Estado e Educação. Campinas: Alínea, 2008.

FRIGOTTO, Gaudêncio. Educação e a crise do capitalismo real. São Paulo: Cortez, 1995. 
HIRATA, Helena. Competências e divisão social do trabalho no contexto de novos paradigmas produtivos. In: Seminário Internacional Educação Profissional, Trabalho e Competência. CIET/SENAI/CNI, Rio de Janeiro, nov. 96.

HIRATA, Helena. Da polarização das qualificações ao modelo da competência. In: FERRETI, C. J. et al. (org.) Novas tecnologias, trabalho e educação: um debate multidisciplinar. Petrópolis, Rio de Janeiro: Vozes, 1994, p.124-138.

KUENZER, Acácia Z. Desafios teóricos-metodológicos da relação trabalho-educação e o papel social da escola. In: FRIGOTTO, G. (org.). Educação e Crise do Trabalho: perspectivas de final de século. Petrópolis (RJ): Vozes, 2000.

KUENZER, Acácia Z. Educação profissional: categorias para uma nova pedagogia do trabalho. In: Boletim Técnico do SENAC. SENAC: Rio de Janeiro, v.25, n.2, maio/ago., 1999b.

KUENZER, Acácia Z. Pedagogia da Fábrica: as relações de produção e a educação do trabalhador. São Paulo: Cortez. 6. ed., 2002b.

MACHADO, Lucília. Educação Básica, empregabilidade e competência. In: Trabalho e Educação, Belo Horzionte: UFMG, n. 3, jan./jul. 1998.

MARX, K. \& .ENGELS. F. Manifesto Comunista. São Paulo: CHED, 1980.

MARX, Karl. Manifesto do partido comunista. Rio de Janeiro: Global, 1986. 45p.

MARX, Karl. Manuscritos econômico-filosóficos. São Paulo: Boitempo, 2004. 191p.

MARX, Karl. O capital: crítica da economia política. Rio de Janeiro: Civilização Brasileira, 2010. vol. I. 571p.

MÉSZÁROS. István. A teoria da alienação em Marx. São Paulo: Boitempo, 2006. p. $115-192$. 
OHNO, Taiichi. O sistema Toyota de produção: além da produção em larga escala. Porto Alegre: BOOKMAN., 1997.

RAMOS, Marise Nogueira. A Pedagogia das Competências: autonomia ou adaptação? São Paulo: Cortez, 3. ed., 2006.

SOARES, R. D. Concepção socialista da educação e atuais paradigmas de qualificação para o trabalho: notas introdutórias. In: Educação e Sociedade, Campinas, n. 58, p. 142-155, abril/1997.

TAYLOR, Frederick. Princípios da Administração Científica. 8. ed. São Paulo: Atlas, 1990.

\footnotetext{
* Mestra em Educação da Univerisidade Federal de Uberlândia (UFU). Graduada em Pedagogia pela Universidade Estadual de Montes Claros (2003) e pós-graduada lato sensu em Docência do Ensino Superior (FUNORTE) e Administração de Sistemas de Informação (UFLA).

1 No Brasil, o taylorismo/fordismo teve seu declínio a partir da década de 1980.

Nesse período destaca-se a criação do chamado Sistema "S" hoje, composto pelo Serviço Nacional de Aprendizagem Industrial (Senai), Serviço Nacional de Aprendizagem Rural (Senar), Serviço Nacional da Indústria (Sesi), Serviço Nacional de Aprendizagem Comercial (Senac), Serviço Social do Comércio (Sesc), Serviço Brasileiro de Apoio às Micro e Pequenas Empresas (Sebrae), Serviço Nacional de Aprendizagem do Cooperativismo (Sescoop), Serviço Social do Transporte e Serviço Nacional de Aprendizagem do Transporte (Sest/Senat). Essas instituições são responsáveis, até hoje, pela formação e capacitação profissional e de formação social.

Vale destacar que desde sua criação até o final da década de oitenta os trabalhadores formados pelo Sistema "S" eram capacitados pelo chamado modelo de qualificação com características do modelo taylorista/fordista de organização e gestão do trabalho. A partir das mudanças de reestruturação produtiva, iniciada na década de 1980 e acelerada na década de 1990, esses centros de formação viram-se diante de uma nova realidade para a formação da força de trabalho, o que causou mudanças nos seus procedimentos de ensino. Isso será esclarecido no decorrer desse trabalho.

3 Para Kuenzer (2002) a parcialização do trabalho gera a desqualificação do trabalhador promovida pelo capital. Se antes, como artesão o trabalhador necessitava de anos para conhecer profundamente e dominar seu trabalho, agora necessita apenas dominar uma tarefa parcial de um processo produtivo que é bem mais extenso e complexo.

Taiichi Ohno (1912 - 1990) é considerado o criador do Sistema Toyota de Produção e o pai do Sistema Kanban.

5

Sistema de administração da produção que determina que nada deve ser produzido, transportado ou comprado antes da hora exata, ou seja fabrica-se o que, quando e na quantidade solicitada pelo mercado consumidor. Ao reduzir estoques e custos decorrentes da produção economiza-se tempo e capital. 
O desemprego estrutural verifica-se quando o número de desempregados é superior ao número de colaboradores que o mercado quer contratar e esse excesso de oferta de trabalhadores não é temporário. O desemprego estrutural resulta das mudanças da estrutura da economia. O desemprego causado pelas novas tecnologias, como a robótica e a informática, recebe o nome de desemprego estrutural. Ele não é resultado de uma crise econômica, e sim das novas formas de organização do trabalho e da produção. Tanto os países ricos quanto os pobres são afetados pelo desemprego estrutural, um dos graves problemas de nossos dias.

ENVIADO EM: 14.10. 2011

APROVADO EM: 21.11. 2011 